
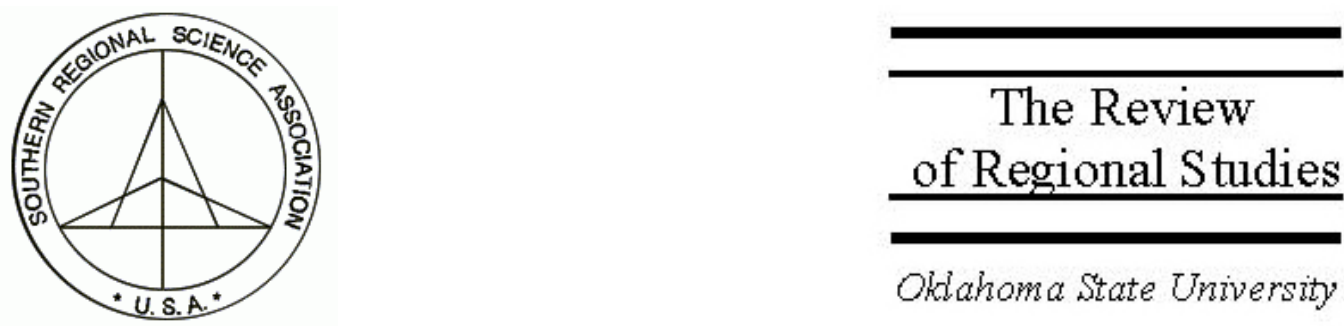

\title{
Regional Unemployment Clusters: Neighborhood and State Effects in Europe and North America
}

\author{
Jose Enrique Garcilazo \\ Regional Competitiveness and Governance Division, Directorate for Public Governance \\ and Territorial Development,OECD, 2, rue André-Pascal, 75775 Paris Cedex 16, France

\section{Vincenzo Spiezia} \\ Economic Analysis and Statistics Division, Directorate for Science, Technology and \\ Industry, OECD, 2, rue André-Pascal, 75775 Paris Cedex 16, France, \\ e-mail: vincenzo.spiezia@oecd.org
}

\begin{abstract}
Recent nonparametric studies find that the regional distribution of unemployment rates is more dependent on geographic location (neighborhood effects) than on national factors (state effects). These results, however, do not control for stochastic dependency between neighborhood and state effects (joint effects) and do not provide any measure of their relative size. In this paper, we construct a simple measure that is invariant in space and across time and compare state, neighborhood, and joint effects in Europe and North America. We find that neighborhood effects are stronger than state effects in Europe, whereas in North America the size of the joint effect is such that one cannot say which effects prevail.
\end{abstract}

Keywords: Nonparametric; Spatial distribution; Regional labor markets

JEL classification: C14; R12; R23 


\section{INTRODUCTION}

Recent studies using nonparametric techniques have begun exploring the spatial dimension of regional unemployment rates (Benito and Ezcurra 2005; Johnson 2000; López-Bazo, Del Barrio, and Artis 2002; Bianchi and Zoega 1999). The evidence points to a link between the geographic location of a particular region and its performance. The two main factors of location are the country in which regions reside (state effects) and their neighboring regions (neighborhood effects), where the latter effects are not necessarily restricted to national borders.

In an influential study, Overman and Puga (2002) measure state and neighborhood effects on unemployment rates among 150 European regions from 1986 to 1995 . They find stronger neighborhood than state effects and conclude that economies of agglomeration explain the empirical evidence as opposed to national labor market institutions. These studies, however, have two major drawbacks. First, they ignore the joint distribution of state and neighborhood effects. Second, they draw conclusions on the relative strength of these effects based on the shape of the estimated distributions, but they do not provide any measure for them.

The aim of this paper is to overcome these drawbacks. As in previous studies, our methodology is based on nonparametric stochastic kernels (Quah 1996a, 1997). However, we further develop this methodology in two innovative directions. First we take into account that if the distributions of unemployment rates across states and neighborhoods are not independent, one cannot completely separate state effects from neighborhood effects. We refer to this probability as joint effects. Second we construct a simple measure of the size of these effects that is invariant across space and time. Based on this measure, we compare state, neighborhood, and joint effects within Europe and North America and between them.

This paper is organized as follows. In Section 2 we provide a review of the literature. The methodology and data are presented in Sections 3 and 4, respectively. Section 5 presents kernel estimates of state and neighborhood effects in Europe and North America. Section 6 introduces the notion of joint effects and proposes a comparable measure of state, neighborhood, and joint effects. Based on this measure, Section 7 compares the size of these effects in Europe and North America. Finally, Section 8 draws some conclusions and suggests implications for further research.

\section{LITERATURE - REGIONAL UNEMPLOYMENT CLUSTERS}

The problem of unemployment has traditionally been studied as a national phenomenon across the Organization for Economic Cooperation and Development OECD. This view attributes cross-sectional variations in national unemployment rates to a series of national labor market characteristics (Scarpetta 1996; Elmeskov, Martin, and Scarpetta 1998, Nickell 1997, Layard and Nickell 1998). The main national characteristics under consideration are active labor market policies, unemployment benefits, benefit duration, 
benefit replacement ratio, tax wedge, degree of coordination, degree of centralization, union density, and union coverage where differences in institutional arrangements yield differences in unemployment rates.

An extension of this view studies the interaction between institutional arrangements with economic shocks to explain differences in cross-sectional rates (Layard, Nickell, and Jackman 1991; Blanchard and Wolfers 2000; Bertola, Blau, and Kahn 2001; Fituoussi et al. 2000), while Belot and van Ours (2004) and Nickell, Nunziata, and Ochel (2005) study the evolution over time by interacting institutions and changes in institutions. While national factors are indeed an important element affecting the rate of unemployment, the unilateral focus in national labor market institutions ignores any internal dynamics within countries. Rates of unemployment at the regional level are very heterogeneous in OECD countries.

At the regional level, differentials in regional rates of unemployment have been studied by three theoretical paradigms: the neo-classical view, the Keynesian view, and a view from the New Economic Geography (NEG).

The neoclassical view regards employment as a positive function of the (marginal) productivity of labor and a negative function of the real wage. In equilibrium, all regions will be in full employment, but low-productivity regions will have lower wages. This view regards regional unemployment primarily as due to inflexibility in the regional wage caused by national labor market institutions such as wage bargaining, unions, taxation, welfare state arrangements, and labor laws. As labor productivity differs among regions, wage setting at the national level would result in unemployment in lowproductivity regions and labor market pressures in the high-productivity ones. The neoclassical view regards regional unemployment as a short-run disequilibrium phenomenon. In the short-run, regional unemployment differentials reflect the slow operation of equilibrating mechanisms (i.e., the response of migration to income and employment differentials, or the relocation of firms to high unemployment regions in search for low-wage labor); while in the long run, regional unemployment differentials will eventually level out and disappear.

Persistence in the neoclassical view is also associated with the concept of "hysteresis," meaning unemployment does not return to any particular value (the natural rate of unemployment) but rather it is determined by the whole history of shocks to the economy. During the process of collective bargaining between union representatives of employed workers (insiders) and firms, the unemployed workers (outsiders) are not represented at the bargaining table. In this case, wages are negotiated so that the expected value of employment remains the same. Due to unexpected shocks in the economy, employment follows a random walk and so would unemployment, which leads to "hysteresis." Models of this type have been developed by Blanchard and Summers (1986) and Gottfries and Horn (1987). 
In the Keynesian view, regional unemployment is primarily caused when the level of aggregate demand is too low to generate full employment. This view predicts that regions specializing in industries for which demand is low (such as low technology or mature industries) will tend to have higher unemployment rates than regions specializing in the dynamic industries of high technology and innovative industries.

Although empirical studies stemming from the neoclassical and Keynesian views establish statistical relationships between a variety of explanatory variables and unemployment (see Elhorst, 2003, for a survey), both theories are challenged by the spatial distribution in unemployment rates, in particular by the fact that low unemployment regions tend to cluster close to each other. Figure 1 displays the regional distribution of unemployment rates in the U.S., where regions (counties) with low unemployment rates (dark red) tend to cluster together. Similar evidence has been reported for Europe (Overman and Puga 2002). Although the observed patterns are not inconsistent with these two theories, there is no theoretical causation mechanism in the neoclassical and Keynesian views that predicts a similar unemployment rate as in neighboring regions.

Models of the NEG, on the other hand, provide an endogenous explanation for this geographic pattern. Since Krugman's seminal 1991 paper, models from the NEG (Krugman 1991; Krugman 1995; Krugman and Venables 1996; Venables 1996; Engelmann and Walz 1995; Puga and Venables 1996; Puga 1998, 1999) have been mainly characterized by: (1) imperfect competition through increasing returns to scale in an economic sector, (2) costs associated with trade or transportation, and (3) forces enhancing (centripetal) or discouraging (centrifugal) agglomeration. The majority of NEG models share the first (1) and second (2) characteristic while they tend to vary their assumptions on (3). The three distinct centripetal forces include: migration of labor (labor mobility between regions), forward and backward linkages, and elasticity of labor supply (labor mobility between sectors).

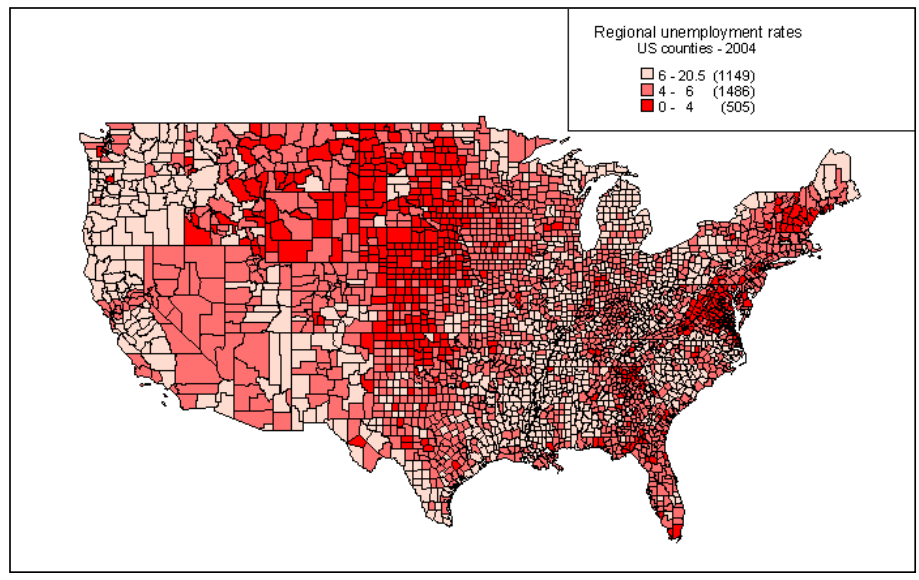

FIGURE 1. Spatial Distribution of Regional Unemployment Rates in the U.S. 
The two main findings stemming from these studies are: under mobility (between regions and between sectors) there is no agglomeration at high trade costs. However, when costs are reduced below a threshold level, agglomeration occurs in one region. On the other hand, the introduction of forward and backward linkages breaks this dichotomy. With high transportation costs, agglomeration does not occur. A decrease below a threshold level produces agglomeration in one region, as in the case of labor mobility; however, if transportation costs are further reduced, agglomeration ceases since wage differentials induce firms to relocate towards regions where lower wages are offered.

All these models assume full employment; thus they cannot explain agglomeration dynamics in labor markets. Two recent models - Epifani and Gancia (2002) and Suedekum (2004) - have added imperfections in the labor market to the framework of the NEG.

The first model departing from the assumption of full employment is by Epifani and Gancia (2002). This model introduces imperfections in the labor market by assuming limited labor mobility and frictions in the matching process between labor supply and labor demand. Centrifugal forces in this model prevail for very high and low trade costs, leading to a symmetric equilibrium (convergence). For an intermediate level of trade costs centripetal forces prevail, leading to agglomeration where a core-periphery pattern emerges. Finally unemployment differentials between the core and the periphery under this model can persist over time if trade costs remain in an intermediate range. The polarization of unemployment differentials occurs if trade costs are reduced between certain parameter values.

Suedekum's (2004) model merges a wage curve representing the labor market with a product market that incorporates an increasing returns scale effect. At equilibrium, when workers are perfectly mobile across regions, the model predicts full agglomeration of economic activity in one region regardless of the level of transportation costs. Under imperfect mobility, agglomeration is enhanced in the larger region (relative to when worker are immobile), however the effects of agglomeration are smaller than under the case of perfect mobility. Thus the model predicts persistence in unemployment rates when transportation costs are present. It associates high wages with regions of lower unemployment rates. Polarization occurs when labor mobility is increased.

Both models can (under certain parameter values) endogenously explain persistence and polarization of regional unemployment rates, and thus they explain why regions with low unemployment rates tend to spatially cluster next to each other.

Neoclassical and NEG theories generate different policy implications. According to the neoclassical view, changes in the labor market institutions will increase flexibility of regional wages and reduce regional unemployment. According to the NEG theory, however, labor market policies alone will be ineffective to reduce unemployment, which is due to lack of agglomeration economies in "peripheral" regions. 
In Section 5 we measure the effects of neighborhood regions and the effects of states on regional unemployment outcomes in Europe and North America. We measure persistence and neighborhood effects through stochastic kernels. This methodology is described in the next section.

\section{METHODOLOGY - STOCHASTIC KERNELS}

Our methodology for assessing country effects and neighborhood effects is through nonparametric stochastic kernels (Quah 1996a, 1997). The choice of a nonparametric technique over a regression-based approach appears better suited to the NEG theory briefly discussed in Section 2. This is so for at least three reasons. First, regression-based approaches construct a conditional "representative" region, averaging across crosssection characteristics. However, if regional unemployment is the result of agglomeration economies arising among neighboring regions, then no region can be taken as "representative" and no region can be studied in isolation independently of others. Instead, the interactions across all regions need to be analyzed. A nonparametric technique can provide a picture of the entire cross-section distribution, while regression-based analysis is not designed for this purpose (Quah 1996a).

Second, NEG models suggest significant two-way interactions between aggregate and disaggregate variables: neighborhoods affect regions, and regions in turn affect neighborhoods. Because the interaction is two-way, regional unemployment cannot be modeled as a function of neighborhood unemployment. Stochastic kernels, instead, permit analysis of the joint distribution of aggregate and disaggregate variables (Quah 1996b).

Finally, NEG theories involve different relations between different parts of the disaggregated distribution, e.g., agglomeration economies in the "core" and negative spillovers among regions in the "periphery." Then summary statistics of the distribution - say a conditional mean or cross-sectional variance - will be inappropriate for understanding the relation between disaggregates and aggregates. Nonparametric techniques instead permit flexible analysis of the entire distribution of regions and permits explicit patterns of cross-section interaction clustering together in distinct clumps to endogenously emerge (Quah 1996b).

The traditional approach for measuring the joint distribution of two stochastic variables is through a probability matrix (Quah 1993), which partitions both distributions into a discrete number of intervals and counts the number of observations in each of the cells resulting from all possible combinations of the two distributions. The limitation of this approach is that arbitrary discretization of the state space alters the probabilistic properties of the data (Bulli 2001).

Stochastic kernels overcome this limitation as they estimate a continuous distribution based on a probability matrix when the number of ranges tends to infinity. In particular, they permit estimation of the conditional probability that the unemployment rate of a 
region is close to: (1) the unemployment rates of the country it belongs to, and (2) the unemployment rate of its neighboring regions. The first probability measures the state effect, and the second probability measures the neighborhood effect, both effects correspond with a specific value of the conditioning variable. Differently said, we estimate the probability that any region has a high, intermediate, or low unemployment rate given that its county/neighborhood has a high, intermediate, or low unemployment rate. The stochastic kernels presented in this paper are computed with a Gauss routine, ${ }^{1}$ which uses a Gaussian kernel with the bandwidth selection recommended by Silverman (1986), as described in the Appendix.

We find it useful to present the kernel estimates in three different ways. The first representation is the 3-D graph plotted in Figure 2 (kernel maps). The y-axis measures the unemployment rate in regions, the $\mathrm{x}$-axis the value of the conditioning variable (unemployment rate in the state or neighborhood), while the z-axis measures the conditional probability of regional unemployment rates. The positive diagonal on the $x-y$ space indicates all points where the regional unemployment rate is equal to the unemployment rate of its state/neighborhood. Thus, if the conditioning variable had a strong effect on regional unemployment rates, the probability mass measured on the zaxis should concentrate around the positive diagonal. On the contrary, if state/neighborhood effects are weak, the probability mass will be scattered away from the positive diagonal.

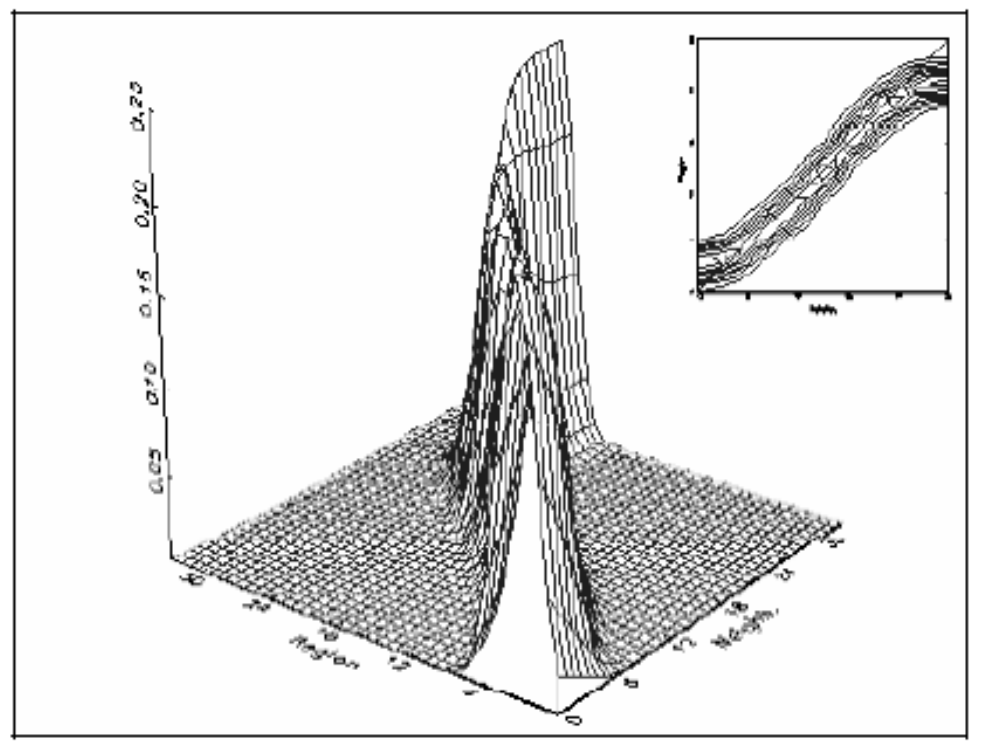

FIGURE 2. Kernels Maps and Contour

\footnotetext{
${ }^{1}$ The routine was developed by George Shuetrim and modified by López-Bazo.
} 
The second representation is the contour on the top-right of Figure 2. This is the 2-D equivalent of the previous graph, where the probability mass under the 3-D plot is depicted as concentric areas - the larger the number of "circles," the larger the probability mass. Thus, the higher the probability concentrated along the positive diagonal, the stronger the state/neighborhood effects.

The final representation is shown in the conditional probability matrix displayed in Table 1. This is the discrete approximation of the continuous probability distribution plotted in Figure 2. (See Equation A5 in the Appendix.) In particular, the cells on the diagonal of the matrix (shown as shaded) measure the probability mass along the diagonal of Figure 2. The probability on the diagonal of the matrix provides, therefore, a simple measure of the size of state/neighborhood effects in correspondence with each value of the conditioning variables. We will return on this point in Section 5.

\section{DATA DESCRIPTION}

Our dataset differs significantly from those of previous studies for both its regional grid and geographic coverage. For the European Union (EU), we use the finest regional grid set by the OECD (TL3) to measure state and neighborhood effects. This finer grid captures possible heterogeneity within the larger NUTS 2 regions used in the majority of studies. In addition, we include regions from Switzerland and Norway because of their geographic proximity, similar language (for Switzerland), and strong commercial ties with regions in the EU. These inclusions provide additional data observations that enrich the analysis.

We also measure state and neighborhood effects in Europe during the late 1990s and early 2000s. Up to now these effects have not been measured during this particular period of intense European integration where new policies have been implemented at the regional, national, and supranational level.

Finally, our analysis goes beyond Europe and explores whether neighborhood and state effects in North American regions (U.S. and Canada) follow a similar pattern as in Europe. We argue that in the latter case, neighborhood effects are present by the nature of their geographic proximity, a shared language, and a common economic policy (NAFTA). Although there is evidence of strong interdependence among U.S. and Mexican border regions (Hansen, 2001), Mexico's exceptionally large informal economy makes its labor market data incompatible. For these reasons, Mexico is not included into our analysis. 
TABLE 1

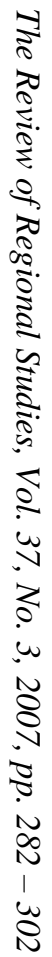

\begin{tabular}{|c|c|c|c|c|c|c|c|c|c|c|c|c|c|c|c|c|c|c|c|c|c|}
\hline & \multicolumn{21}{|c|}{ Regional Unemployment (Percent) } \\
\hline & 0.0 & 1.7 & 3.3 & 5.0 & 6.6 & 8.3 & 9.9 & 11.6 & 13.2 & 14.9 & 16.5 & 18.2 & 19.8 & 21.5 & 23.1 & 24.8 & 26.4 & 28.1 & 29.7 & 31.4 & 33.0 \\
\hline \multirow{21}{*}{ 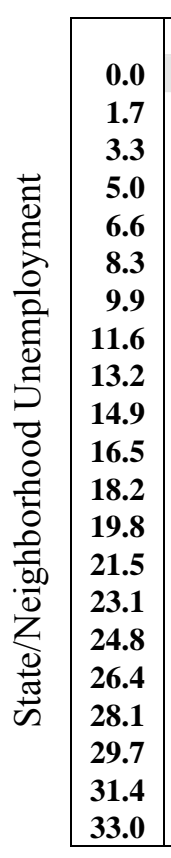 } & 5 & 3 & 2 & 1 & 0 & 0 & 0 & 0 & 0 & 0 & 0 & 0 & 0 & 0 & 0 & 0 & 0 & 0 & 0 & 0 & 0 \\
\hline & 23 & 19 & 15 & 8 & 3 & 1 & 0 & 0 & 0 & 0 & 0 & 0 & 0 & 0 & 0 & 0 & 0 & 0 & 0 & 0 & 0 \\
\hline & 40 & 39 & 34 & 24 & 12 & 3 & 1 & 0 & 0 & 0 & 0 & 0 & 0 & 0 & 0 & 0 & 0 & 0 & 0 & 0 & 0 \\
\hline & 25 & 28 & 32 & 32 & 25 & 13 & 5 & 1 & 0 & 0 & 0 & 0 & 0 & 0 & 0 & 0 & 0 & 0 & 0 & 0 & 0 \\
\hline & 6 & 9 & 14 & 23 & 30 & 27 & 16 & 6 & 1 & 0 & 0 & 0 & 0 & 0 & 0 & 0 & 0 & 0 & 0 & 0 & 0 \\
\hline & 1 & 1 & 3 & 9 & 21 & 31 & 29 & 18 & 6 & 1 & 0 & 0 & 0 & 0 & 0 & 0 & 0 & 0 & 0 & 0 & 0 \\
\hline & 0 & 0 & 0 & 2 & 8 & 18 & 28 & 29 & 17 & 5 & 1 & 0 & 0 & 0 & 0 & 0 & 0 & 0 & 0 & 0 & 0 \\
\hline & 0 & 0 & 0 & 0 & 1 & 6 & 16 & 27 & 27 & 13 & 4 & 1 & 0 & 0 & 0 & 0 & 0 & 0 & 0 & 0 & 0 \\
\hline & 0 & 0 & 0 & 0 & 0 & 1 & 5 & 14 & 26 & 26 & 14 & 3 & 0 & 0 & 0 & 0 & 0 & 0 & 0 & 0 & 0 \\
\hline & 0 & 0 & 0 & 0 & 0 & 0 & 1 & 4 & 16 & 30 & 26 & 9 & 2 & 0 & 0 & 0 & 0 & 0 & 0 & 0 & 0 \\
\hline & 0 & 0 & 0 & 0 & 0 & 0 & 0 & 1 & 6 & 18 & 28 & 20 & 10 & 3 & 1 & 0 & 0 & 0 & 0 & 0 & 0 \\
\hline & 0 & 0 & 0 & 0 & 0 & 0 & 0 & 0 & 1 & 6 & 18 & 30 & 25 & 11 & 3 & 1 & 0 & 0 & 0 & 0 & 0 \\
\hline & 0 & 0 & 0 & 0 & 0 & 0 & 0 & 0 & 0 & 1 & 9 & 24 & 30 & 23 & 13 & 6 & 2 & 1 & 0 & 0 & 0 \\
\hline & 0 & 0 & 0 & 0 & 0 & 0 & 0 & 0 & 0 & 0 & 2 & 10 & 21 & 29 & 28 & 20 & 11 & 5 & 3 & 3 & 3 \\
\hline & 0 & 0 & 0 & 0 & 0 & 0 & 0 & 0 & 0 & 0 & 0 & 2 & 9 & 23 & 33 & 33 & 28 & 24 & 22 & 21 & 21 \\
\hline & 0 & 0 & 0 & 0 & 0 & 0 & 0 & 0 & 0 & 0 & 0 & 0 & 2 & 9 & 17 & 27 & 37 & 42 & 44 & 44 & 44 \\
\hline & 0 & 0 & 0 & 0 & 0 & 0 & 0 & 0 & 0 & 0 & 0 & 0 & 0 & 1 & 4 & 11 & 19 & 23 & 25 & 28 & 28 \\
\hline & 0 & 0 & 0 & 0 & 0 & 0 & 0 & 0 & 0 & 0 & 0 & 0 & 0 & 0 & 1 & 2 & 4 & 5 & 5 & 5 & 5 \\
\hline & 0 & 0 & 0 & 0 & 0 & 0 & 0 & 0 & 0 & 0 & 0 & 0 & 0 & 0 & 0 & 0 & 0 & 0 & 0 & 0 & 0 \\
\hline & 0 & 0 & 0 & 0 & 0 & 0 & 0 & 0 & 0 & 0 & 0 & 0 & 0 & 0 & 0 & 0 & 0 & 0 & 0 & 0 & 0 \\
\hline & 0 & 0 & 0 & 0 & 0 & 0 & 0 & 0 & 0 & 0 & 0 & 0 & 0 & 0 & 0 & 0 & 0 & 0 & 0 & 0 & 0 \\
\hline
\end{tabular}


TABLE 2

Unemployment Rates Descriptive Statistics: 1998-2004

\begin{tabular}{lccrclc}
\hline & Regions & Observations & Mean & Max & Min & St. Dev. \\
\hline Europe & 706 & 4,942 & 8.47 & 35.8 & 0.3 & 5.65 \\
North America & 249 & 1,748 & 6.00 & 28.8 & 1.86 & 3.05 \\
Total & $\mathbf{9 5 5}$ & $\mathbf{6 , 6 9 0}$ & $\mathbf{7 . 8 2}$ & $\mathbf{3 5 . 8}$ & $\mathbf{0 . 3}$ & $\mathbf{5 . 2 1}$
\end{tabular}

To sum up, our dataset (Table 2) includes about 1,000 regions from North America (Canada and the United States), the EU (including the new member countries), Switzerland, and Norway. Our regional categorization corresponds to the OECD TL3 classification, which consists of NUTS 3 regions in the EU, cantons in Switzerland, counties (Fylkers) in Norway, Bureau of Economic Analysis (BEA) Economic Areas in the U.S., and Canadian Census Economic Areas.

We measure and compare state and neighborhood effects between Europe and North America. In Europe, the state effects correspond to effects at the country level, in the U.S. at the level of states, and in Canada at the level of provinces. State effects, as defined in all three cases, each maintain a level of autonomy relative to a federal or, in the case of Europe, supranational government; and each has a common set of polices such as taxation mechanisms or labor legislation that affects outcomes in their respective labor markets. For the case of Europe, the state effects can be associated with the effects of national labor market institutions.

In the BEA classification, some economic regions include counties from more than one state. The state effects in this case are a weighted average unemployment rate across all the states belonging to the BEA area. Each weight corresponds to the proportion of labor force of all BEA counties belonging to that state relative to the total labor force in the BEA area. The sum of all weights adds to one. Neighborhood unemployment rates are computed as the weighted average of the unemployment rates of the neighboring regions, where the weights are given by the proportion of labor force of each region to the whole neighborhood.

\section{STATE AND NEIGHBORHOOD EFFECTS IN EUROPE AND NORTH AMERICA}

Figure 3 displays state and neighborhood effects on unemployment rates for 736 European TL3 regions over the period 1998-2004. The distribution of regional unemployment rates - conditional on the neighborhood's unemployment rates - appears concentrated along the diagonal. This indicates that a region will have a high probability of attaining a low, intermediate, or high unemployment rate when the unemployment rates of its neighboring regions are also low, intermediate, or high. 


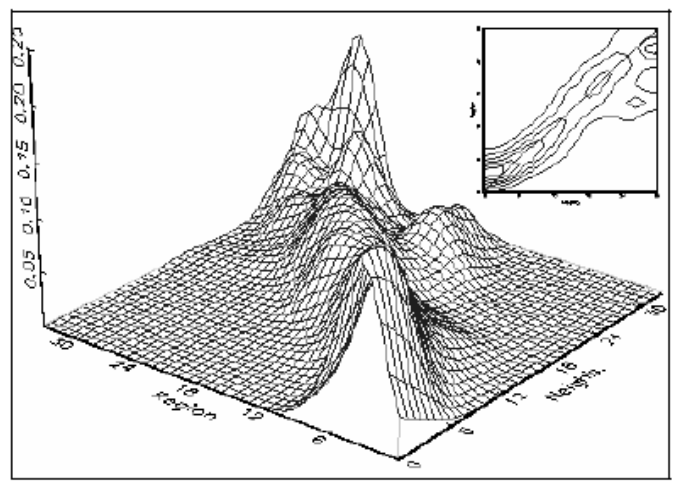

(a) Neighborhood Effects

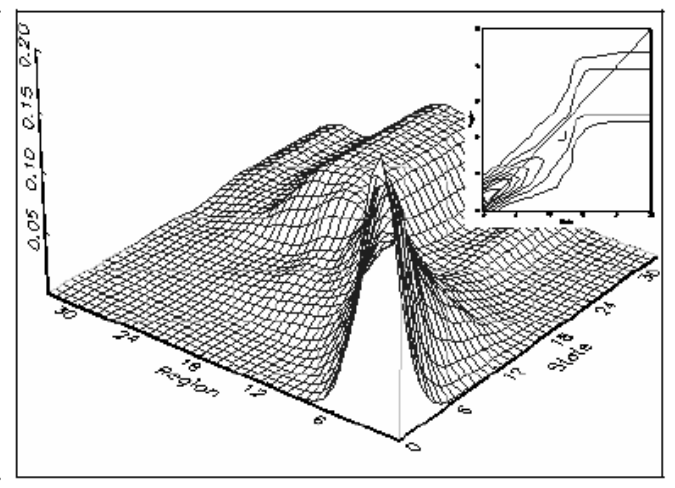

(b) State Effects

FIGURE 3. Stochastic Kernels - 736 European TL3 Regions, 1998-2004

A small group of regions, represented by the island of probability mass below the diagonal on the right, is the exception to this pattern and shows unemployment rates systematically below neighboring regions. This group includes a few regions in Poland (Gdansk-Gdynia-Sopot, Miasto Wroclaw, Miasto Lódz) and in the south of Italy (Trapani, Ragusa, Benevento and Salerno).

The distribution of regional unemployment rates - conditional on the country's unemployment rates - appears centered along the diagonal only for low to medium rates of unemployment. This means that a region from a country with a low (intermediate) unemployment rate has a higher probability of having a low (intermediate) unemployment rate. In contrast, countries with high unemployment rates seem to have little effect on regional unemployment. A small group of regions, represented by the islands of probability mass below the diagonal on the left, are the exception to this pattern and show unemployment rates systematically below those of their countries. These regions are mostly in Poland (Miasto Poznan; Miasto Warszawa, Miasto Kraków and GdanskGdynia-Sopot) and in the Slovak Republic (Bratislavský kraj and Trencianský kraj). In conclusion, while neighborhood effects can be detected along the whole range of regional unemployment rates in Europe, state effects are present only in European countries with low to medium unemployment rates.

Figure 4 displays the state effects (provinces in Canada and states in the U.S.) and neighborhood effects for 238 North American regions. The state effects in North American regions follow a similar pattern as in Europe: they appear significant only in states with low and medium unemployment rates. This means that North American regions from states or provinces with low unemployment rates have a higher probability of attaining low unemployment rates. On the other hand, states or provinces with high unemployment rates do not precondition regional outcomes, i.e., regions can attain low 


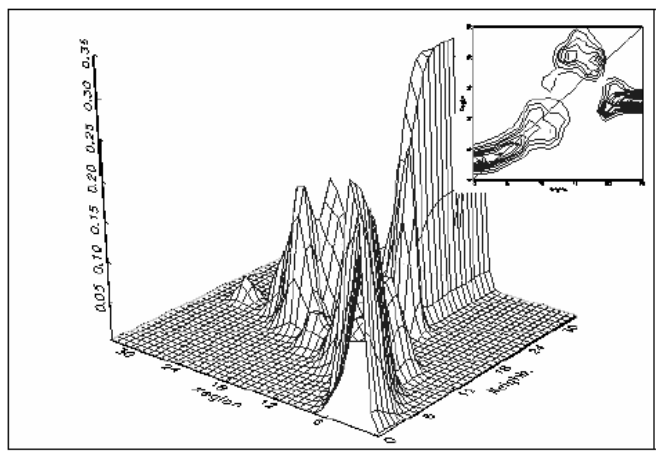

(a) Neighborhood Effects

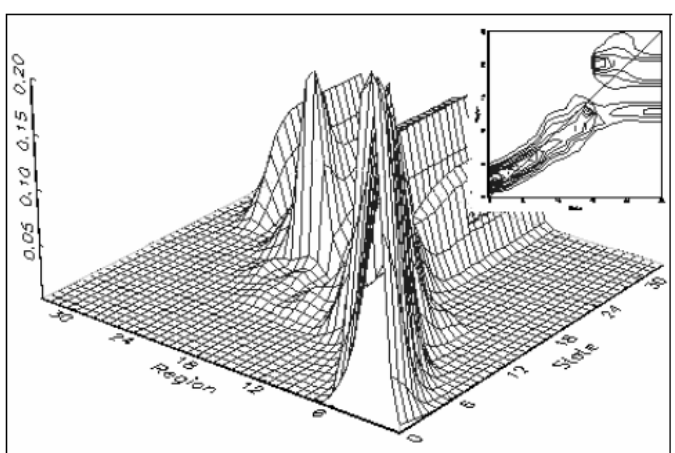

(b) State Effects

FIGURE 4. Stochastic Kernels - 238 North American Regions, 1998-2004

unemployment rates even if they belong to a state or a province with weak labor market performances.

The neighboring pattern observed in Europe breaks down in the case of North America. While regions with low and medium unemployment rates also tend to have low and medium unemployment rates, high-unemployment neighborhoods seem to have little effect on regions. This is shown by the two probability masses, the first on the left above the diagonal (regions performing worse than their neighborhoods) and the second on the right below the diagonal (regions performing better than their neighborhoods).

In conclusion, state effects can be detected only in "states" with low to medium unemployment rates, whereas "states" with high unemployment do not seem to affect regional outcomes. This pattern can be found both in North America and Europe. Neighborhood effects are present in all European regions; in North America, however, neighborhoods with high unemployment rates do not seem to affect regional outcomes.

\section{JOINT EFFECTS}

The kernel graphs shown in the previous section reveal the existence of state and neighborhood effects, but they do not say anything about their size. This piece of information, however, is necessary in order to compare the relative strength of these effects in space and over time. To construct a measure of these effects, it is convenient to use the conditional probability matrixes - one conditional on states, the other conditional on neighborhoods - corresponding to the kernel estimates plotted in Figure 3 (Europe) and Figure 4 (North America).

As observed in Section 3, the cells on the diagonal of the matrix measure the probability mass along the diagonal of the kernel map (Figures 3 and 4). Therefore, the probability on the diagonal of the matrix provides a simple measure of the size of state/ 
neighborhood effects corresponding with each value of the unemployment rate of states/ neighborhoods.

To allow comparability between state and neighborhood effects on the one hand and between Europe and North America on the other, we have partitioned the probability space into the same number of cells with an equal range. In particular, we use a $21 \times 21$ matrix - like the one shown in Table 1 - where the range of each cell is equal to the difference between the highest and the lowest unemployment rate of the whole dataset (i.e., Europe and North America together) divided by the number of intervals (21). This partition implies that the cells on the diagonal add up to about 5 percent of the probability space of the matrix. As all probabilities have been measured based on the same matrix grid, the probability distributions can be compared between geographic areas (Europe and North America) and conditioning variables (state and neighborhood).

The main drawback of the kernel estimates as presented in Section 5 is that they condition the distribution of regional unemployment rates either on state or neighborhood, but they ignore the joint distribution of the conditioning variables. This omission has two major consequences for the results. First, if the distributions of unemployment rates across states and across neighborhoods are not independent, some of the state effects are erroneously classified as neighborhood effects and vice versa. This is so because if the two conditioning variables are not independent, the distribution of regional unemployment conditional on neighborhood (state) will also be depend on the distribution of state (neighborhood) unemployment.

Second, if there is some probability that unemployment rates in states and neighborhoods are equal, one cannot separate state from neighborhood effects as the unemployment rate of a region would be equal to both the rate of its neighborhood and the rate of its state. We define this probability as joint effect.

By defining $R, S$, and $N$ as the unemployment rate in regions, states, and neighborhoods, respectively, and $P_{R, S}$ and $P_{R, N}$ as their joint distributions, we compute the following probabilities.

$$
\begin{array}{ll}
P_{R, S}(R=S \mid S=j) * P_{R, N}(R \neq N \mid N=i) & \forall i=j \quad i, j=1, \ldots \ldots, 21 \\
P_{R, N}(R=N \mid N=i) * P_{R, S}(R \neq S \mid S=j) & , \\
P_{R, S}(R=S \mid S=j) * P_{R, N}(R=N \mid N=i) & ,
\end{array}
$$

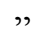

Equation (1) measures the conditional probability that a region's unemployment rate is equal to the rate of its state but not to the rate of its neighborhood. This corresponds to the probability on the positive diagonal of the state matrix (Figures $3 \mathrm{~b}$ and $4 \mathrm{~b}$ for Europe and North America, respectively) times the probability outside the positive diagonal of 
the neighborhood matrix (Figures $3 \mathrm{a}$ and $4 \mathrm{a}$ ). Thus, this probability provides a measure of the state effect, controlling for the effect of neighborhood. ${ }^{2}$

Equation (2) measures the conditional probability that a region's unemployment rate is equal to the rate of its neighborhood but not to the rate of its state. This corresponds to the probability on the positive diagonal of the neighborhood matrix (Figures $3 \mathrm{a}$ and Figure 4a for Europe and North America, respectively) times the probability outside the positive diagonal of the state matrix (Figures $3 \mathrm{~b}$ and $4 \mathrm{~b}$ ). Thus this probability provides a measure of the neighborhood effect, controlling for the effect of state.

Finally, Equation (3) measures the conditional probability that a region's unemployment rate is equal to both the rate of its neighborhood and the rate of its state when the two are equal. This corresponds to the probability on the positive diagonal of state matrix (Figures $3 \mathrm{~b}$ and $4 \mathrm{~b}$ for Europe and North America, respectively) times the probability on the positive diagonal of the neighborhood matrix (Figures 3a and 4a). Since in this case one cannot separate the state effect from the neighborhood effect, we define this measure as joint effect.

\section{STATE VERSUS NEIGHBORHOOD: MEASURING RELATIVE EFFECTS}

Based on Equations 1-3, our aim is to: (1) measure the size of state, neighborhood, and joint effects in each region and (2) compare the overall effects of state and neighborhood on the regional distribution of unemployment rates in Europe and North America.

Figure 5 compares neighborhood effects between North America and Europe over the whole range of unemployment rates. It is apparent that the effects of neighborhood are different in the two geographic areas. Neighborhood effects appear stronger in North America than in Europe for low and medium unemployment rates (between 3.3 and 9.9 percent), while the opposite is true for very low (below 3.3 percent) and for high and very high unemployment rates (above 9.9 percent). The only exception to this pattern is the strong neighborhood effect in North America corresponding to the unemployment rate around 18 percent. This exception is entirely due to a few high-unemployment neighborhoods in Canada (West Coast-Northern Peninsula-Labrador, Notre DameCentral Bonavista Bay, South Coast-Burin Peninsula, and Avalon Peninsula). For unemployment rates above 20 percent, neighborhood effects disappear in North America while they remain large in Europe.

State effects also tend to be stronger in North America than in Europe but on a wider range of unemployment rates (Figure 6). Not only are state effects in North America stronger corresponding with high-medium unemployment rates (particularly between

\footnotetext{
${ }^{2}$ This probability is clearly affected by the size of the matrix; the larger the matrix, the lower the probability space on its diagonal. The results presented below are based on a $21 \times 21$ matrix, which leaves about 5 percent of the probability space on the diagonal. We have repeated the analysis based on a $11 \times 11$ matrix, i.e., about 10 percent of the probability space, but this does not change the nature of the results
} 
8.25 and 13.20 percent) but also for high and very high unemployment rates. On the contrary, state effects in Europe are larger than in North America corresponding with very low unemployment rates (below 3.3 percent), but they tend to disappear with very high unemployment rates

Figure 7 completes the picture by showing the probability that the unemployment rate of a region is equal both to the unemployment rate of its neighboring regions and to the unemployment rate of its country when these two rates are equal. In these circumstances, it is not possible to separate the neighborhood effect from the state effect. Figure 7 shows that the joint effect tends to be higher in North America than in Europe, suggesting that the differences in unemployment rates between neighborhoods and states are larger in Europe than in North America.

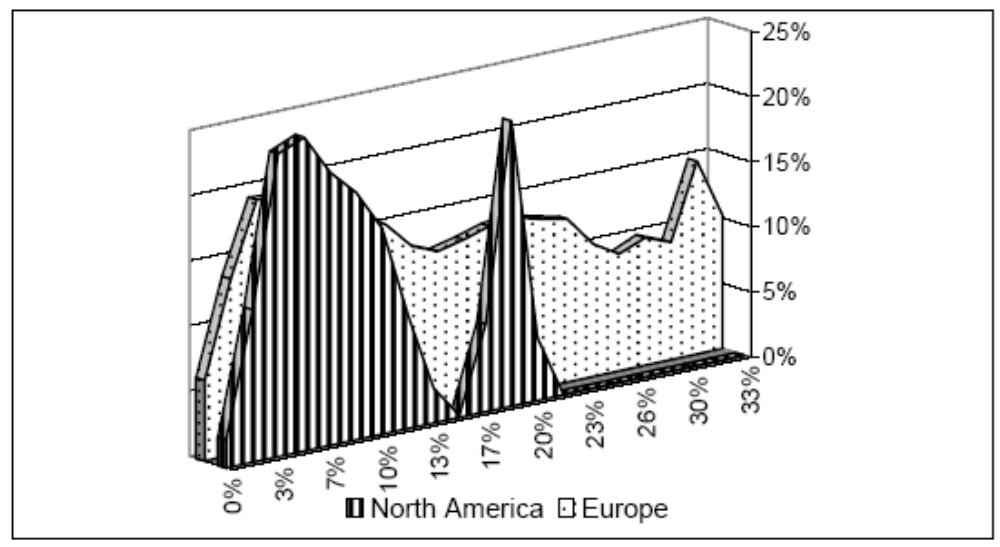

FIGURE 5. Neighborhood Effects - Europe and North America

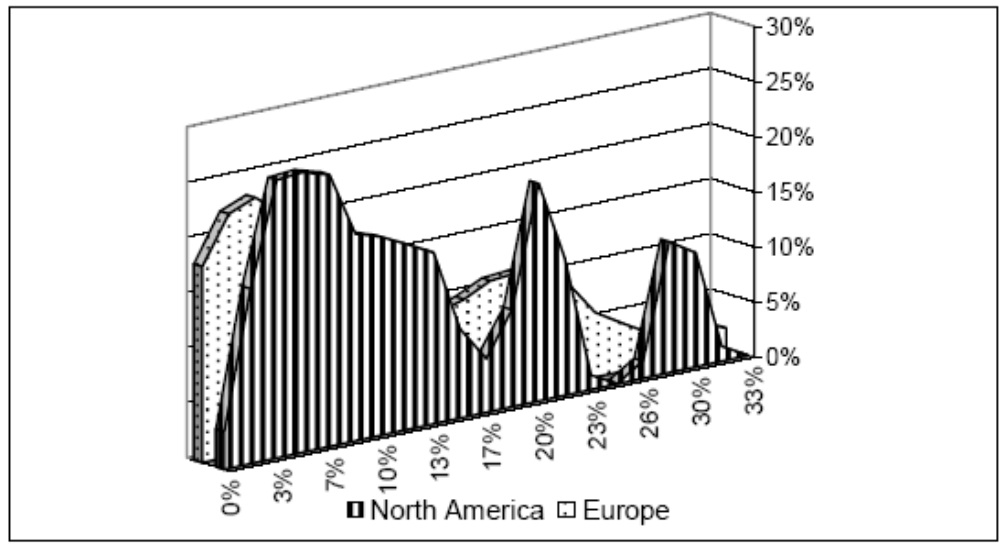

FIGURE 6. State Effects - Europe and North America 


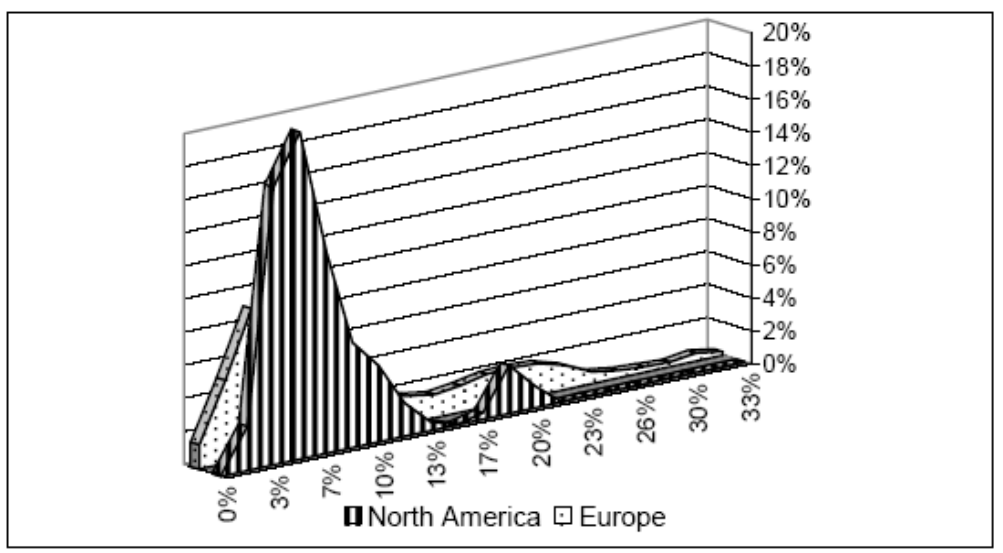

FIGURE 7. Joint Effects - Europe and North America

Our final aim is to measure the extent to which the regional distribution of unemployment rates is explained by state or neighborhood effects. In fact, given the conditional probability distributions - conditional on a specific value of the unemployment rate in a state or neighborhood - the overall effect will depend on the joint distribution of the conditioning variables. The joint distribution of neighborhood and state unemployment is computed in a standard way as the matrix product between the joint distribution of regional and neighborhood unemployment and the conditional distribution of state on regional unemployment, both matrixes generated by the kernels estimates of Section 5 .

Denoting $P_{N, S}, P_{N}$, and $P_{S}$ as the joint and the marginal distributions of neighborhood and state unemployment rates, respectively, we can compute the following probabilities.

$$
\sum_{j=1}^{21} P_{R, S}(R=S \mid S=j) * P_{R, N}(R \neq N \mid N=i) *\left[P_{S}(S=j)-P_{N, S}(N=i ; S=j)\right] \quad \forall i=j
$$

$$
\sum_{i=1}^{21} P_{R, N}(R=N \mid N=i) * P_{R, S}(R \neq S \mid S=j) *\left[P_{N}(N=i)-P_{N, S}(N=i ; S=j)\right]
$$

$$
\sum_{i=1}^{21} P_{R, S}(R=S \mid S=j) * P_{R, N}(R=N \mid N=i) * P_{N, S}(N=i ; S=j)
$$

Equation (4) measures the proportion of the regional distribution of unemployment rates accounted for by state effects, Equation (5) the proportion accounted for by neighborhood effects, while Equation (6) measures the joint effects. Figure 8 shows the size of these effects in Europe and North America. 
State and neighborhood effects together appear significantly stronger in North America than in Europe. Above 70 percent of the regional distribution of unemployment rates is not accounted for by state, neighborhood, or joint effects. In North America, this proportion is below 65 percent. This finding suggests that while neighborhoods and states are among the major drivers of regional labor market performance in North America, the main explanation for unemployment differentials among European regions must lie somewhere else. This finding is confirmed by the differences in the joint effects. In North America, unemployment rates of neighborhoods are closer to unemployment rates of the states/provinces, so the effects of states and neighborhoods tend to overlap. On the contrary, neighborhoods and states are less related in Europe, so that their effects are more likely to differ.

Finally, neighborhood effects in Europe (14.0 percent) are larger than state effects (12.0 percent), whereas in North America state effects (15.9 percent) seem to prevail over neighboring effects (14.5 percent). However, the size of the joint effects in North America (5.1 percent) is such that it could push the balance in favor of either state or neighborhood effects. Therefore, one cannot say which of the two effects is dominant.

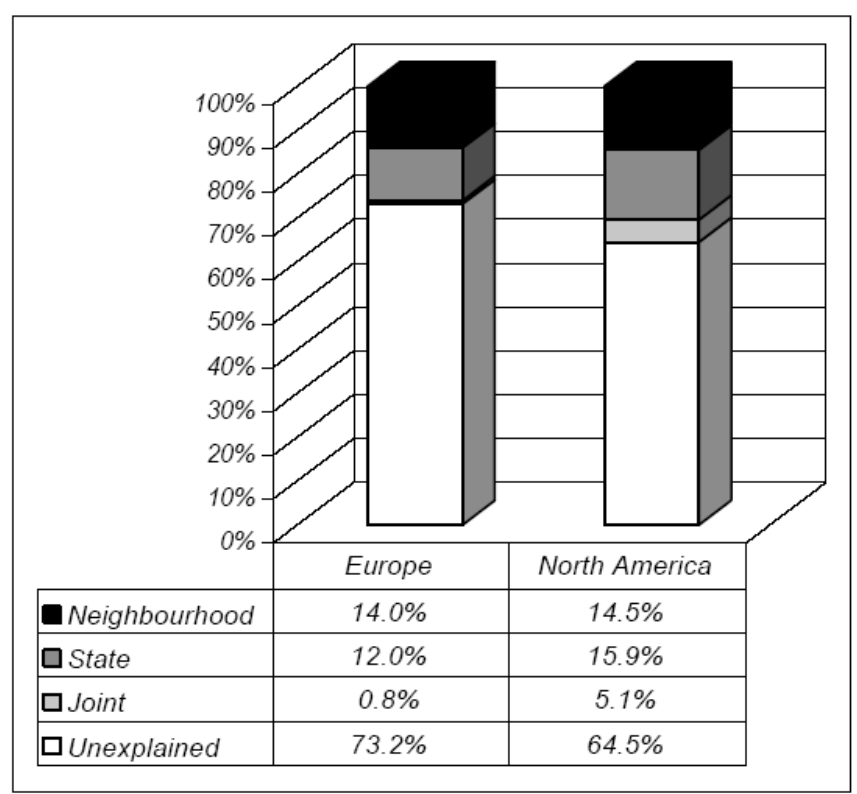

FIGURE 8. Overall Effects of State and Neighborhood on Regional Distribution of Unemployment, Europe and North America, 1998-2004 


\section{CONCLUSIONS}

In this paper, we measured state and neighborhood effects in about 1,000 regions from Europe and North America over the period 1998-2004 using nonparametric stochastic kernels. We developed the methodology used in previous studies in two directions. First, we examined the joint effects due to the overlapping of state and neighborhood effects; second, we constructed a simple measure of these effects that is invariant in space and across time. Based on these measures, we found a number of interesting results. First, state and neighborhood effects together appear significantly stronger in North America than in Europe. This suggests that North American regions show higher responsiveness to their economic environments - neighboring regions or states - whereas European regions show a more idiosyncratic pattern. These findings seem consistent with the view that regional disparities in unemployment rates are larger in Europe than in North America because of lower flexibility of regional wages in Europe.

Second, neighborhood effects in Europe appear larger corresponding with high unemployment rates: regions in a neighborhood with high unemployment rates also have a high probability of high unemployment rates. This negative effect is not detected in North America, where high-unemployment neighborhoods have virtually no impact on their regions. As a result, high-unemployment regions tend to cluster in space in Europe while they are more scattered in North America. These findings suggest the existence of "core-periphery" equilibrium in Europe, with high unemployment concentrated in "peripheral" regions. Therefore, labor market policies alone are not likely to reduce unemployment without measures to generate agglomeration economies.

Finally, we find evidence that regional differences in unemployment rates in Europe are better explained by geographic location (neighborhood effects) than by national factors (state effects). This finding further supports the view that regional unemployment disparities in Europe are mainly due to economies of agglomeration - or lack of them rather than national labor market institutions. However, the relative size of these effects in North America remains uncertain due to the large joint effect arising from the overlapping of state and neighborhood effects. Thus a different analytical approach seems necessary to disentangle these effects.

\section{REFERENCES}

Belot, M. and J.C. van Ours, 2004. "Does the Recent Success of Some OECD Countries in Lowering Their Unemployment Rates Lie in the Clever Design of Their Market Reforms," Oxford Economic Papers 56, 621-642.

Benito, J.M. and R. Ezcurra, 2005. "Spatial Disparities in Productivity and Industry Mix: The Case of the European Regions," European Urban and Regional Studies 12(2), 177-194.

Bertola, G., F.D. Blau, and L.M. Kahn, 2001. "Comparative Analysis of Labor Market Outcomes: Lessons from the U.S. from International Long-Run Evidence," NBER Working Paper 8526. 
Bianchi, M. and G. Zoega, 1999. "A Nonparametric Analysis of Regional Unemployment Dynamics in Britain," Journal of Business and Economic Statistics 17(2), 1-12.

Blanchard, O. and J. Wolfers, 2000. "The Role of Shocks and Institutions in the Rise of European Unemployment: The Aggregate Evidence," The Economic Journal 110, C1-C33.

Blanchard, O.J. and L. Summers, 1986. "Hysteresis and the European Unemployment Problem," in S. Fisher (ed.), NBER Macroeconomics Annual. MIT Press: Cambridge, MA, 15-78.

Bulli, S., 2001. "Distribution Dynamics and Cross-Country Convergence: A New Approach," Scottish Journal of Political Economy 48(2), 226-243.

Elhorst, J.P., 2003. "The Mystery of Regional Unemployment Differentials: A Survey of Theoretical and Empirical Explanations," Journal of Economic Surveys 17, 709-748.

Elmeskov, J., J.P. Martin, and S. Scarpetta, 1998. "Key Lessons for Labour Market Reforms: Evidence from OECD Countries' Experiences," Swedish Economic Policy Review 5, 205-252.

Engelmann, F.C. and U. Walz, 1995. "Industrial Centers and Regional Growth in the Presence of Local Inputs," Journal of Regional Science 35(1), 3-27.

Epifani, P. and G. Gancia, 2002. "Geography, Migrations and Equilibrium Unemployment," CESPRI Working Paper 128.

Fitoussi, J.P., D. Jestaz, E.S. Phelps, and G. Zoega, 2000. "Roots of the Recent Recoveries: Labor Reforms or Private Sector Forces," Brookings Papers on Economic Activity 1.

Gottfries, N. and H. Horn, 1987. "Wage Formation and Unemployment Persistence," Economic Journal 97, 877-886.

Hansen, G., 2001. "U.S. - Mexico Integration and Regional Economics: Evidence from Border-City Pairs," Journal of Urban Economics 50, 259-287.

Johnson, P.A., 2000. "A Nonparametric Analysis of Income Convergence across the U.S. States," Economics Letters 69, 219-223. , 2005. "A Continuous State Space Approach to "Convergence by Parts," Economics Letters 86, 317-321.

Krugman, P., 1991. "Increasing Returns and Economic Geography," The Journal of Political Economy 99(3), 483-499.

, 1995. "Globalization and the Inequality of Nations," The Quarterly Journal of Economics CX.4, 857-880.

Krugman, P., and A.J. Venables, 1996. "Integration, Specialization, and Adjustment," European Economic Review 40, 959-967.

Layard, R. and S. Nickell, 1998. "Labour Market Institutions and Economic Performance," in O. Ashenfelter and D. Card (eds.), Handbook of Labor Economics. Vol. 3 C. North Holland: Amsterdam.

Layard, R., S. Nickell, and R. Jackman, 1991. "Unemployment: Macroeconomic Performance and the Labour Market," Oxford University Press: Oxford.

López-Bazo, E., T. Del Barrio, and M. Artis, 2002. "The Regional Distribution of Spanish Unemployment: A Spatial Analysis," Papers in Regional Science 81(3), 365-389. 
Nickell, S., 1997. "Unemployment and Labor Market Rigidities: Europe versus North America," Journal of Economic Perspectives 11 (3), 55-74.

Nickell, S., L. Nunziata, and W. Ochel, 2005. "Unemployment in the OECD since the 1960s: What Do We Know," The Economic Journal 115.500, 1-27.

Overman H. and D. Puga, 2002. "Unemployment Clusters across European Regions and Countries," Economic Policy 34, 117-147.

Puga, D., 1998. "Urbanization Patterns: European versus Less Developed Countries," Journal of Regional Science 38(2), 231-252.

, 1999. "The Rise and Fall of Regional Inequalities," European Economic Review 43, 303-334.

Puga, D. and A.J. Venables, 1996. "The Spread of Industry: Spatial Agglomeration in Economic Development," Journal of Japanese and International Economies 10, 440464.

Quah, D.T., 1993. "Galton's Fallacy and Tests of Convergence Hypothesis," Scandinavian Journal of Economics 95, 427-443. , 1996a. "Regional Convergence Cluster across Europe," European Economic Review 40, 951-958.

, 1996b. "Aggregate and Regional Disaggregate Fluctuations," Empirical Economics 21(1), 137-159.

, 1997. "Convergence Empirics across Economies with (Some) Capital Mobility," Journal of Economic Growth 1, 27-59.

Scarpetta, S., 1996. "Assessing the Role of Labour Market Policies and Institutional Settings on Unemployment: A Cross Country Study," OECD Economic Studies 2 (26), 43-82.

Suedekum, J., 2004. "Increasing Returns and Spatial Unemployment Disparities," HWWA Discussion Paper 256.

Silverman, B.W., 1986. Density Estimation for Statistics and Data Analysis. Chapman and Hall: New York.

Venables, A., 1996. "Equilibrium Locations of Vertically Linked Industries," International Economic Review 37(2), 341-359.

\section{APPENDIX}

Assuming a first-order, Markov, Johnson (2000, 2005) and Durlauf, Johnson, and Temple (2005) based on Quah (1997) propose to describe the relationship between two distributions as:

$$
f_{t+\tau}(z)=\int_{0}^{\infty} g_{\tau}(z \mid x) f_{t}(x) d x
$$

where the stochastic kernel $g_{\tau}(z \mid x)$ is a conditional density of $z$ conditional on $x$, and $\tau$ is the period ahead transition when measuring changes over time. The ratio of the joint density to the marginal density provides the estimate of the kernel as follows. 
First the joint density of $z$ and $x$ is estimated using a Gaussian kernel by multiplying two univariate Gaussian kernels to obtain the product kernel for the joint density through the equation:

$$
\hat{f_{K}}(x, z)=\frac{1}{n} \sum_{i=1}^{n} \frac{1}{h_{x} \sqrt{2 \pi}} e^{-0.5\left(\frac{x-x_{i}}{h_{x}}\right)^{2}} \frac{1}{h_{x} \sqrt{2 \pi}} e^{-0.5\left(\frac{x-x_{i}}{h_{x}}\right)^{2}} .
$$

The criterion for computing bandwidths $h_{x}$ and $h_{y}$ are as recommended by Silverman (1986) given by:

(A3) $h=0.9 A n^{-1 / 5}$

where $A=\min$ (standard deviation, interquartile range/1.34)

The local bandwidth factors, inversely related to the joint estimate given by (A2) are multiplied with the bandwidths $h_{x}$ and $h_{y}$ to estimate the adaptive joint density of $z$ and $x$. This joint density is next integrated over $z$ to obtain the marginal distribution of $x$.

$$
\hat{f}(x)=\int_{-\infty}^{\infty} \hat{f}_{A}(x, z) d z
$$

Finally by dividing the estimated joint density over the estimated marginal distribution we obtain the estimate for the stochastic kernel $\hat{g}_{\tau}(z \mid x)$ as shown in Equation A5:

(A5) $\quad \hat{g}_{\tau}(z \mid x)=\frac{\hat{f}_{A}(x, z)}{\hat{f}(x)}$. 